ARTÍCULOS

\title{
La oralidad linguiística en tiempos de COVID-19. Un aporte teórico al discurso formal
}

\section{Linguistic orality in times of pandemic. A theoretical contribution to the formal discourse}

Jaén, Franklin E.

Franklin E. Jaén

franklin.esteban@up.ac.pa.

Universidad de Panamá, Panamá

\section{Delectus}

Instituto Nacional de Investigación y Capacitación Continua, Perú ISSN-e: 2663-1148

Periodicidad: Semestral

vol. 5, núm. 1, 2022

publicaciones.iniccperu@gmail.com

Recepción: 02 Agosto 2021

Aprobación: 06 Septiembre 2021

Publicación: 22 Enero 2022

URL: http://portal.amelica.org/ameli/ jatsRepo/390/3902822002/index.html

Esta licencia permite a otros entremezclar, ajustar y construir a partir de su obra con fines no comerciales, y aunque en sus nuevas creaciones deban reconocerle su autoría y no puedan ser utilizadas de manera comercial, no tienen que estar bajo una licencia con los mismos términos.

\section{c) (7) (8)}

Esta obra está bajo una Licencia Creative Commons AtribuciónNoComercial 4.0 Internacional.
Resumen: El propósito es analizar la oralidad lingüística en tiempos de pandemia y el aporte teórico que subyace al discurso formal. Se considera el enfoque cualitativo, tipo de investigación teórica documental, apoyada en un diseño bibliográfico de carácter analítico e interpretativo. Las técnicas e instrumentos de recolección de datos utilizados son la observación documental, el análisis de contenido y, una matriz de registro de las fuentes de información secundarias revisadas. Como consideraciones finales, se plantea el impacto que la actual crisis sanitaria ha generado que términos como covid-19, coronavirus, confinamiento o PCR formando parte de un lenguaje covídico de uso cotidiano, haciendo que el idioma se adapte al nuevo panorama léxico. Por otra parte, la caracterización e importación al castellano de palabras de otros idiomas, el trasvase de términos desde los lenguajes especializados a la cotidianidad, la creación de nuevas palabras con motivación irónica, así como el tecnicismo exacerbado de uso común.

Palabras clave: Oralidad, lingüística, pandemia, interpretación paradigmática, organización formal.

Abstract: The purpose is to analyze linguistic orality in times of pandemic and the theoretical contribution that underlies formal discourse. The qualitative approach is considered, a type of documentary theoretical research, supported by a bibliographic design of an analytical and interpretive nature. The data collection techniques and instruments used are documentary observation, content analysis and a registry matrix of the secondary information sources reviewed. As final considerations, the impact that the current health crisis has generated that terms such as covid-19, coronavirus, confinement or PCR, are part of a covid language of daily use, making the language adapt to the new lexical landscape. On the other hand, the characterization of the import into Spanish of words from other languages, the transfer of terms from specialized languages to the common, creation of new words with ironic motivation, as well as an exaggerated technicality of common use.

Keywords: Orality, linguistics, pandemic, paradigmatic interpretation, formal organization. 


\section{INTRODUCCIÓN}

La oralidad se corresponde con el proceso de comunicación ya sea de carácter verbal, vocal o corporal/no verbal, entre dos o más interlocutores presentes en un mismo espacio. Señala Arnoux Puentes (2015) que dentro de los factores que la caracterizan se encuentran:

El lingüístico, referido a la articulación clara, el uso preciso de palabras y la construcción correcta de oraciones. El extralingüístico, indicando la entonación, la cadencia, el ritmo, las pausas y el volumen de la voz. El discursivo, que se orienta en la construcción del discurso de acuerdo con una intención. Socio-lingüístico, que enmarca el conocimiento del contexto cultural en el cual se produce el hecho verbal y, el cultural, referido a la comprensión general y particular que se tiene sobre el tema tratado (p. 22).

De esta manera, representa un sistema simbólico de expresión, es decir, un acto de significado dirigido entre humanos de ineterés para la vida en sociedad, en sus diferentes escenarios, formales e informales. Por lo cual se considera el eficiente medio de comunicación que facilita la socialización, la transmisión de conocimientos, entre otros.

En un estudio desarrollado por Barrios Cuevas (2016) denominado "El lenguaje y la comunicación en el siglo XX", indica que la transmisión de las esferas del saber se da en un alto porcenteje por vía oral. De ahí que, la función social básica y fundamental de esta consista en permitir las relaciones sociales. Sin embargo, y a pesar de lo anteriormente dicho, el autor enfatiza que, la escritura es el sistema de expresión que mayor prestigio tiene, sin tomar en cuenta que los conceptos de oralidad y escritura hacen referencia solamente a dos modos distintos de producción del lenguaje, cada uno con sus características y, sobre todo con sus normas propias de funcionamiento.

Al referirse a la oralidad y planificación discusiva Ferrari Muss (2016), en su investigación titulada "La riqueza del multienfoque de la linguística en la lengua oral”, señala que la lengua hablada es espontánea e instantánea, considerándose la conversación como la formas más natural de la oralidad, encontrándose en esta normas que orienta su coherencia discursiva desde el imbricamiento gramatical. Se interpreta que, la oralidad adquiere distintos matices en su discurso formal en función del escenario en el cual se desarrolle. De ahí que sus géneros prototípicos pueden usarse en los ámbitos académicos, medios de comunicación, político y judicial, empresarial, religiosos, entre otros.

En consideración Bolívar Acosta (2017) refiere en "Una aproximación teórica a la lingüística comunicacional en la postmodernidad" que las características generales de la oralidad formal son los rasgos contextuales, discursivos y lingüísticos que prevalecen en el sistema comunicacional que se genera, el cual va a resultar impactado por las diversas manifestaciones en la social y cultural que desempeñan un papel fundamental en la construcción de identidades.

Entendiendo el carácter comunicacional social de la oralidad y la pertinencia del discurso en función del contexto, en la actualidad, cobra importancia el impacto que la COVID-19, ha generado en esta. Señala Adames Ponce (2020):

La pandemia ha dejado desconcertados a todos. El cambio cultural que se ha producido en la comunicación y las formas de hablar han afectado a los habitantes del mundo entero. Y eso significa que se ha agregado nuevas palabras al lenguaje cotidiano, que antes solo se utilizaban en un contexto profesional y técnico (p.45).

Es así como palabras, hasta ahora desconocidas por la gran mayoría, han conseguido hacer que el registro de las conversaciones, como medio representativo de la oralidad, haya pasado de ser coloquial a formal. De igual manera, Puertas Nance (2020) establece que:

La oralidad se traduce en todo un desafío antes de la pandemia, la llegada de la crisis del coronavirus lo ha complicado aún más. Se convive entre webinars, clases online, reuniones de trabajo, presentaciones de doctorados, videoconferencias o cualquier tipo de reunión. Todos esos eventos se celebran, con la impersonalidad que eso conlleva (p.77). 
De ahí que, tanto el lenguaje como los medios a través de los cuales se genera la comunicación en esta pandemia, han querido desarrollar desde la heterogeneidad lingüística formal una oralidad de unificación de criterios para aproximarse a una correcta terminología de uso colectiva. Sobre ejemplo de esto afirma Velandria Martínez (2020):

La enfermedad provocada por la pandemia ha sido etiquetada como COVID-19 y se sabe que está inducida por el coronavirus asociado a la COVID-19, también llamado SARS-CoV-2 (coronavirus-2 del síndrome respiratorio agudo grave, de la sigla inglesa SARS, severe acute respiratory syndrome), para diferenciarlo del SARS-CoV, identificado hace unos diecisiete años (p.12).

Así como lo referido por el autor, a manera de ejemplo, sin duda en la oralidad, el uso de la lengua y la terminología merecen un lugar y reflexión, en virtud, que no solo se ha generado un nuevo discurso social, sino que, en algunos casos, producto de la rapidez en la que se produce por los interlocutores el mensaje, se han desarrollado los llamados vicios orales. Estos son definidos como el uso inadecuado del léxico o a la construcción incorrecta de frases y oraciones que dificultan la interpretación del mensaje (Terrado Herrera, 2020, p.12).

Desde esta cosmovisión, surge el interés y propósito de este estudio en analizar la oralidad lingüística en tiempos de COVID-19 y el aporte teórico que subyace al discurso formal. Entendiendo que la mirada crítica del estudio se orienta a entender los desafios que las palabras tienen como poder e impacto innegables sobre la humanidad y su entorno, siendo básicas en la construcción de una comunicación exitosa.

\section{METODOLOGÍA}

Esta investigación utiliza el paradigma cualitativo, el tipo de investigación documental, de acuerdo a lo referido por Arias Lozano (2016) corresponde con "una estrategia de comprensión y análisis de realidades teóricas mediante la revisión de distintas fuentes documentales, a través de un abordaje sistemático y organizado" (p.23). De allí que el diseño asume el carácter bibliográfico ocupándose de la revisión a través de fuentes documentales físicas y electrónicas.

El procedimiento de la investigación atiende al esquema planteado Véliz Ancón (2016, p.77) para los estudios documentales, efectuado de acuerdo con los siguientes pasos:

1. Ubicación y arqueo de fuentes bibliográficas y documentales: textos, foros, seminarios, artículos de revisas científicas, entre otros, que permitieran obtener la información pertinente del objeto de estudio.

2. Selección de las fuentes apropiadas para recoger datos relevantes.

3. Validación de las fuentes seleccionadas.

4. Lectura detallada de las fuentes seleccionadas, relacionada con los eventos de estudio.

5. Localización y ficheo del material relevante.

6. Codificación y sistematización de la información seleccionada con el registro de esta en el análisis acorde a sus contenidos.

7. Redacción y construcción de los aspectos teóricos que describen y explican los eventos.

8. Establecimiento y descripción de las categorías de los eventos objeto de estudio para los cuales se pretende identificar relaciones.

9. Análisis de los datos aportados en relación con los eventos de estudio, a través de la clasificación y descripción de estos.

10. Generación de las conclusiones y consideraciones finales de la disertación investigativa.

Dentro de las etapas concretas del proceso, posteriormente se realiza la sistematización e integración de los datos, para finalmente, triangularlos y generar la correspondiente organización del producto de investigación 
documental. De esta manera, se entiende que para la extracción/recopilación de la literatura se analizaron los objetivos, el fundamento teórico y los principales resultados presentados en las investigaciones identificadas, tomando solo las aportaciones pertinentes al objetivo de esta investigación. Del análisis de los autores consultados se desarrolla el constructo teórico que sustenta el estudio.

Con respecto a la obtención de los datos, la búsqueda bibliográfica se realizó durante los meses de enero de 2020 a mayo 2021, accediendo a través de internet a la literatura recogida en los buscadores como el Google y el Google Académico, utilizando los tesauros bibliotecológicos en el área de lingüística y oralidad.

Se resalta que se utilizaron filtros obteniéndose un total de 30 documentos. Tras la lectura del resumen de estos, se preseleccionaron 15. Posteriormente, se efectuó una lectura en detalle y se seleccionaron y revisaron los artículos y trabajos a través de la parrilla de lectura crítica CASPe (Critical Appraisal Skills Programme Español) (Véliz Ancón, 2016). Finalmente, el número fuentes analizadas fueron 11.

Sobre los criterios de inclusión:

- Idioma: español e inglés.

- Temporalidad:2016-2020.

- Acceso libre completo y gratuito.

- odo tipo de artículos aportados por las bases de datos anteriormente descritas protocolos, artículos, tesis sobre el tema.

Criterio de exclusión:

- El material documental no se ajusta a los criterios de inclusión ya descritos con anterioridad.

Las técnicas utilizadas son la observación documental, presentación resumida del texto y el resumen analítico. Como instrumentos: fichas; computadoras y sus unidades de almacenajes, cuadros de registros y clasificación de categorías; así como la matriz de análisis. Se utilizaron como técnicas de procesamiento de la información: el análisis de contenido y el círculo hermenéutico-dialéctico de Lincoln y Guba.

\section{RESULTADOS}

De los documentos consultados para determinar el estado teórico que permitiera dar respuesta al propósito del estudio, estos se clasificaron en una secuencia cronológica, configurándose la matriz de análisis con cuatro (4) categorías:

La COVID-19 y la oralidad

De las referencias consultadas, se logró en el análisis concretizar que:

La oralidad, desde ópticas de diferentes teóricos, tiene en cuenta no solo los elementos lingüísticos, supralingüísticos y paralingüísticos relacionados, conjuntamente, con el objetivo de la comunicación y la intención del hablante al expresarse; sino también el aspecto socio-lingüístico, haciendo mención a lo contextual. De ahí que, el mensaje es comprendido en la medida en que el oyente comparte una serie de representaciones sociales que le permiten acceder al contexto y, al conjunto de supuestos linguísticos que maneja al momento de la interacción oral, en este caso con la situación pandemica y los referentes que forman parte de esta (Barrios Cuevas, 2016, p.77).

El contexto holístico de significados, vinculados a la COVID-19, que sirven de soporte a la oralidad subyacen en entender los escenarios desde donde se subscribe el proceso, llámese social o humano. Los desafíos se orientan en entender que el leguaje coloquial y cotidiano, que se ha llenado de terminología especializada, pasa a ser formal como práctica en la que la realidad discursiva se inscribe en el contextos social y cultural. La aceptación del tecnicismo como rasgo para responder a la diversidad lingüística. Todo 
esto implica ampliar el desarrollo de convenciones pragmáticas y socioculturales involucradas en contextos globales y tecnologizados (Corrado Atanacio, 2017, p.42).

La oralidad concibe un contexto definido por parámetros extralingüísticos que condicionan de manera inmediata la actividad discursiva identificándose como: Situación de producción: Incluye los elementos del enunciador, el destinatario y el objetivo del discurso para dar referencia a un contexto discursivo. Situación de recepción: Es el espacio propio en que el discurso es procesado por el destinatario, tomando en consideración los elementos propios del receptor con los que decide interpretar el mensaje. Se refiere a esta como contexto de uso o situación. Situación de interacción: Representada como la zona de cooperación donde se produce la comunicación social, en la que cada uno adopta cierto rol definido por el tipo de conectividad en la que participa y la comprensión de la pandemia (Ferrari Montiel, 2016, p.12).

La construcción discursiva ante la COVID-19

Terminologías de uso casi exclusivos limitado a ámbitos médico-sanitarios, hasta ahora desconocidas por la gran mayoría, han conseguido hacerse parte del registro de conversaciones de la cotidianidad de las personas (Arnoux Puentes, 2015, p.33). Ejemplos:

Conversación via whassap:

"Desde que se declaró la situación de alarma por el brote de coronavirus, no salgo de casa sin mi mascarilla, mis guantes y mi gel hidroalcohólico con distanciamiento social"

Sección de noticias de la televisión:

"Según la OMS, el periodo de incubación puede llegar a ser de 24 días, en los que existe un alto riesgo de propagación comunitaria por la acción patógena del virus”.

En el análisis de los ejemplos se aprecia cómo estos enunciados que, a simple vista, encajarían en un contexto comunicativo informal entre amigos o compañeros, adquieren un tono más formal y riguroso, simplemente por el hecho de utilizar esas nuevas palabras. Todo un léxico que ha pasado a ser tendencia absoluta en conversaciones, medios de comunicación y redes sociales. Ya no se habla de mantener la distancia, sino de distanciamiento social para evitar la propagación comunitaria de persona a persona.

“...Nos encontramos en un estado de emergencia de salud pública ante un brote pandémico, indicó el gobierno"

No se dice que "...el gobierno ha decretado el estado de alarma".

"Necesitamos aplanar la curva de contagios..."

El término curva, que hasta ahora se utilizaba en contextos como las curvas del camino, en la actualidad adquiere otra cognotación.

Uso de eufemismos y formalidades:

Sustitución de palabras de uso cotidiano y frecuente (Adames Ponce, 2020, p.23). Ejemplos:

Denominación de médicos, enfermeras y auxiliares, por personal sanitario. Sus jefes son las autoridades sanitarias. Referirse a la Organización Mundial de la Salud por sus siglas, OMS.

No se está encerrado en casa, sino confinados". Un equipo de mascarilla y guantes son ahora kits de protección o EPIs. Además, se ha dejado de tener dolores, tos, o sensación de faltar el aire. Ahora se tiene sintomas, dolencias, o insuficiencia respiratoria. Si, por el contrario, no se ha desarrollado ninguno de estos males, entonces se considera asintomáticos.

\section{Palabras e invenciones:}

Neologismos incorporados que amplian el novedoso repertorio de terminología COVID19.

Covidiota, referido aquel que ignora los protocolos, no respeta las normas y rompe el aislamiento colaborando con el contagio del virus.

Covidartículos y Coviprecios. Compra durante la semana Coviprecios y ahorra en todos los Covidartículos un $19 \%$.

Covidmodo, cuando alguien decide pasar el fin de semana tranquilo y sin salir de casa. 
Se considera que un imperativo académico y de tecnicismo de áreas del saber, se transfirió a la oralidad social, en la cual aparte de gozar del conocimiento específico, refuerza y ostententa el poder de la palabra, lo cual permite compartir conocimientos. Y en el contexto lingüístico hacer de comunicación oral un instrumento pertinente y de amplitud de acción.

El desafío se traduce en atender cada vez más los modos de participación dentro del campo de la lingüística y la oralidad, atendiendo a plantearse y dar respuestas a las siguientes interrogantes: ¿Se utilizan correctamente estas nuevas palabras?; ¿ Conoce el ciudadano común su significado?. En consecuencia, solo si se conoce su significado exacto se hará el uso apropiado dentro de baterías de términos en el contexto oral de la pandemia.

Desde otra línea del pensamiento, se indica que otro gran reto que se presenta en la oralidad en pandemia y su vinculación con el discurso deriva del doble compromiso con los avances de esta disciplina y, los cambios de la sociedad. Por un lado, es fundamental adaptarse a las tecnologías y entrar de manera decidida a la transdisciplinariedad y; por otro, es necesario articular la teoría con la práctica para mejorar la explicación de los significados en la dinámica social. El desafío sigue siendo la confrontación de paradigmas, desde un debate epistemológico que hay que enfrentar de manera directa para describir la oralidad en contextos dinámicos y vinculantes con la interacción social (Malavè Enrìquez, 2015, p.18).

Conocer el discurso oral humano como creador de realidades y vehículo de significados sociales e ideológicos, para considerar su valor en la convivencia social. Para ello, el mayor desafío es redefinir su objetivo, método y objeto, ya que como consecuencia de los enfoques interdisciplinarios, a menudo, se pierde de vista qué es lo netamente lingüístico (Ponte Villareal, 2016, p.34).

\section{Vicios orales y COVID-19}

Se enfatiza el arraigo en la comunicación oral de un discurso con prevalencia de vicios de dicción lingüística que genera el empleo de vocablos inadecuados (D'Sousa Carmet, 2015, p.23), tales como:

El objetivo es que no hayan más víctimas mortales

Se han triplicado el número de casos

Seguirán habiendo contagios

Si hubieran nuevos casos, se plantearía otras estrategia

Se pueden ver a los sanitarios en la escalera del hospital

Siguen habiendo medidas que tomar

Uno de cada tres contagios se registran en el entorno familiar

Se van a testar a 30.000 personas.

Presencia de los vulgarismos, definidos como la construcción innecesaria de las palabras o alteración de su sentido semántico. Ejemplos: ¿Quién lo indució a no seguir la curentena? por ¿Quién lo indujo a no cumplir la cuarentena? (Ponte Villareal, 2016, p.56).

Uso de cacofonía, se indica como el sonido desagradable que se produce por el encuentro o repetición de las mismas sílabas dentro de una oración. Ejemplos: Tómate un té de jengibrey te aliviarás (Puertas Nance, 2020, p.54).

La redundancia, pleonasmo vicioso que consiste en emplear vocablos innecesarios, que solo repiten ideas ya expresadas. Ejemplo: Es necesario limpiar con el limpiador las superficies y la ropa. Estas situaciones, condicionan la comunicación oral, por lo que reulta un desafío superar la pobreza léxica ( $\mathrm{D}$ 'Sousa Carmet, 2015, p.23).

De tal manera que, el coronavirus ha generado en el ámbito de la oralidad lingüística consecuencias impredecibles en el llamado lenguaje Covid-19. De expansión rápida, la pandemia y, en su corolario ha configurado su propio campo semántico, imponiendo un léxico en todos los idiomas del planeta, incluyendo el de pueblos indígenas. 


\section{DISCUSIÓN}

En función de los resultados y del objetivo planteado, como conclusiones, se precisa entender inicialmente a la oralidad lingüística, dejando de considerar al lenguaje como único y verdadero objeto de la comunicación oral, sino entenderlo integrado en contextos reales, como en el caso de la pandemia (D'Sousa Carmet, 2015, p.23). Por tanto, la oralidad resulta acumulativa, abundante y redundante, conservadora, participante y situacional; es decir, no es abstracta, siempre está presente en el momento que se necesite.

Por consiguiente, desde que comenzó la pandemia, se inicia una oralidad configurada de un repertorio de términos, expresiones y terminologías especializadas que se vulgarizaron convirtiéndose en moda. Esto se articula con lo señalado por Adames Ponce (2020), cuando afirma, que lo excepcional en el lenguaje pandémico, ha sido la vulgarización del lenguaje científico que se fue incorporando en todos los idiomas del mundo. Surgiendo una serie de expresiones a las cuales, la sociedad en su oralidad cotidiana, ha ido familiarizándose. Un corolario semántico con un léxico amplio.

Asimismo, una compleja situación es analizada por Puertas Nance (2020) quien enfatiza el uso de la oralidad y el contexto social en que se produce las nuevas formas de hablar. Se resalta la prevalencia de tres fenómenos de creación léxica que han primado: la importación al castellano de palabras de otros idiomas, el inglés principalmente, el trasvase de términos desde los lenguajes especializados al común, como PCR o antígenos, y la creación de nuevas palabras con una motivación irónica, como cuarenpena o covidiota.

Respecto a los tecnicismos, autores como Adames Ponce (2020), Terrado Herrera (2020) y, Velandria Martínez (2020), explican que hay palabras o significados nuevas, como confinar, que pueden permanecer posterior al virus. En otros casos, hay creaciones que son meramente fenómenos pasajeros, como coronabonos, que desaparecerán, ya que, responden a necesidades del momento.

\section{CONCLUSIONES}

La oralidad lingüística en tiempos de COVID-19, el lenguaje es dinámico y está en constante actualización. Por otro lado, existen factores externos que condicionan el cambio lingüístico y, uno de ellos es el entorno social. En este sentido, la lengua refleja el pensamiento de los hablantes, entendiendo que en el discurso forma, el componente léxico es el más notorio, actualizándose constantemente, según el hablante y la coyuntura de la cotidianidad existente. Entendiendo que la pandemia ha provocado un cambio cultural que ha afectado a la oralidad y la comunicación a nivel global, conjuntamente, con el dinamismo social, ya que, el lenguaje también es la forma en que se define la sociedad y las relaciones con las personas.

\section{REFERENCIAS}

Arnoux Puentes, E. (2015). La linguística y la oralidad: Aportes fundamentales. Tesis, Universidad de Buenos Aires, Argentina.

Adames Ponce, V. (2020). El lenguaje de la pandemia: ¿Cómo el coronavirus ha cambiado la manera de hablar?. Educause Horizon Report Learning Edition. pp. 2-58. EDUCAUSE.

Arias Lozano, A. (2016). El Proyecto de investigación. Introducción a la metodología científica. (8va, Ed.). Episteme.

Barrios Cuevas, T. (2016). El lenguaje y la comunicació en el siglo XXI. UPEL-IMPM.

Bolívar Acosta, A. (2017). Una aproximación teórica a la linguística comunicacional en la postmodernidad. Tesis, Universidad Central de Venezuela, Linguistica, Caracas. Venezuela.

Corrado Atanacio, J. (2017). ¿Cómo enterner la comunicación linguística desde la transcomplejidad? Tesis, Universidad Autónoma de México, Linguística, Méxido D.F.

D'Sousa Carmet, D. (2015). La oralidad: características del español usado en Internet. Editora Hucitec. 
Ferrari, S. (2016). La riquesa del multienfoque de la linguística en la lengua oral. Tesis, Universidad De Los Andes, Humaninades y Letras, Mérida. Venezuela.

Malavé Enriquez, C. (s.f.). La escritura y la informática. Siglo XXI Editores.

Nieto Alargón, M. (2015). Metodología de la Investigación. Ediciones de la U. P.

Palacios Arias, S. (2016). Comunicación, lenguaje y contexto. Ayuso.

Ponte Villareal, T. (2016). El discurso oral. Tesis Doctoral, Universidad Central de Venezuela, Facultad de Linguística, Caracas. Venezuela.

Puertas Nance, V. (2020). Pandemia COVID-19 y el lenguaje. Anuario de Lingüística. Universidad de Valladolid.

Terrado Cárdenas, L. (2015). El español y la oralidad: Creación y cambios culturales. Fondo de Cultura.

Terrado Herrera, P. (2020). Análisis del discurso en pandemia. Visor.

Velandria Martínez F. (2020). La pandemia deja huella en la lengua española.

Véliz Ancón, O. (2016). Metodología de la Investigación holística. Revista Sociedad. Lingüística, 2. pp.45-52. 